\title{
Sufficiency Economy Philosophy: An Enabler for Zero Waste City
}

\author{
Kannikar Khaw-ngern', Nattakitt Udomphol ${ }^{2}$, Phra Tinnawat Suksong (candapanno) ${ }^{3}$, Chainarong \\ Khaw-ngern ${ }^{4}$ \\ ${ }^{1,2,3}$ Faculty of Buddhism, ${ }^{4}$ Faculty of Humanities, \\ 1,2, 3,4 Mahachulalongkornrajavidyalaya University \\ ${ }^{1}$ kannikar.khaw@gmail.com, ${ }^{2}$ nattakittu@gmail.com, ${ }^{3}$ candapanno@gmail.com, ${ }^{4}$ chainarong.kha@ mcu.ac.th
}

\begin{abstract}
Waste has become a critical problem in cities around the world. Each year, the world generates 2.01 billion tonnes of municipal solid waste, with at least 33 percent of that not managed in an environmentally safe manner. The currently consumption-driven lifestyle also produces a huge volume of waste each day threatening the world sustainability. Moreover, the ongoing depletion of natural finite resources is also leading the globe to an uncertain future. The purpose of this article is to study the zero-waste concept and the characteristics of zero waste city, to study the principles of sufficiency economy philosophy, and to review the role of sufficiency economy in waste reduction and how it contributes to zero waste city. Documentary study and literature review were used for data collection. The result showed that ineffective waste management including landfill and incineration can be one major cause of waste. Also, overconsumption can be another cause that exacerbates the current waste situation. A zero-waste strategy and the concept of zero waste city can contribute to waste prevention with its proactive-reduce, reuse, and recycle (3R)-principle and to the reduction of wastes sent to landfills and incinerators. Sufficiency Economy Philosophy can also contribute to waste reduction at the consumer side. With the zero-waste strategy and sufficiency economy philosophy, we can achieve waste and pollution reduction and preserve our environment, as well as create sustainability for the future generations.
\end{abstract}

Keywords

Zero Waste, Zero Waste City, Zero Waste Hierarchy, Overconsumption, Sufficiency Economy Philosophy

Article Received: 10 August 2020, Revised: 25 October 2020, Accepted: 18 November 2020

\section{Introduction}

Humans are generating more and more waste on earth and the situation is exacerbated by our overconsumption behaviors. Although lots of people seem not to be bothered by the waste, it doesn't mean they can stay away from the problems of waste. Landfill sites can be a constant threat to the environment as they take up large pieces of land to exist; causing damage to ecosystems, they are a blot on the landscape in our natural surroundings, and they are one of the major causes of toxic contamination of soil. Burning waste in incinerators also produces hazardous air pollutants, such as carbon monoxide and PM 2.5.

In the zero-waste management concept, our current linear economy; take-make-use-dispose, can be identified as a major cause of the excessive amount of waste. To move towards the zero waste, our resources need to be managed in a way of preserving their value and energy in a circularity chain while our overconsumption behavior has to be changed in order to keep our planet away from excessive waste and toxic conditions. To make this happen, a waste preventive policy must be adopted to promote reduce, reuse, and rethink practices, followed by increasing separation in the waste collection at source and quality recycling. Food waste needs to be reduced in the first place, and invested in composting as a means of managing organic waste without releasing methane to the atmosphere but enriching soil instead. E-waste also needs to be effectively managed through innovative reuse solutions and business models built to last. Significantly, overconsumption culture needs to be changed to ensure that we are not taking resources and wasting them over our planet capacity. Moreover, organic waste needs to be treated before landfilling in order to reduce the mass of organic waste in landfills and minimize the methane released to the air.

When successfully reducing the amount of waste sent to landfills and incinerators, cities will be able to implement the zero waste strategies faster and operate the zero waste practices at cheaper cost and in safer manner for the environment comparing to the traditional waste management. To stop the production of excessive waste and the uncontrolled climate change, cities need to replace their waste addictive behavior with sufficiency lifestyle. Sufficiency Economy philosophy is a practical guideline for the traditional lifestyle of Thai society in which all aspects of life are interconnected because it allows peaceful coexistence of different things. Also, the Sufficiency Economy philosophy is a dynamic and systematic principle that can be integrated into economic, social, and environmental development. Thus, the Sufficiency Economy is able to steer the society away from crisis, and can be implemented as guidelines for development in order to keep up with rapid changes in the age of globalization.

\section{Zero Waste}

The definition of zero waste, according to Zero Waste International Alliance (ZWIA), is "Zero Waste: The conservation of all resources by means of responsible production, consumption, reuse, and recovery of products, packaging, and materials without burning and with no discharges to land, water, or air that threaten the environment or human health [1]." It is used as guiding principles of the Zero Waste Hierarchy to create a globally accessible framework for zero-waste practices. It includes both a goal and a plan of action. It aims to maximize 
resource recovery and minimize extraction of scarce natural resources by progressively reducing and ultimately ending waste disposal in incinerators and landfills while moving forward to waste reduction by refusing wasteful products and packaging, encouraging producers to take responsibility for their waste, and encouraging reuse and repair.

The Zero Waste Hierarchy describes a progression of policies and strategies to support the Zero Waste system, from highest and best to lowest use of materials [2]. It is designed to be applicable for all sectors including policy makers, industries, and individuals to change their mindset from waste management to resource management. It aims not only to promote safe waste disposal but also to ensure that the resource value is preserved in the economy for the future generations. Figure 1 illustrates the seven levels of zero waste hierarchy; two levels relating products and five levels relating waste. The first level is to stop waste from being produced by designing waste-free products and banning single-used items. The second level is to scale up the market for used items which still can function in order to preserve resource value and prevent them from being discarded as waste. The third level is moving into the waste area as it is the process of cleaning, repairing, and refurbishing the items that have been thrown away to make them become products again. The fourth level is the process of turning the separately collected waste into secondary raw materials by recycling, composting, and anaerobic digestion. The fifth, sixth, and seventh levels are the processes of extracting valuable materials from waste, managing residuals, and rejecting policies and systems that encourage the destructive disposal of organics [3].

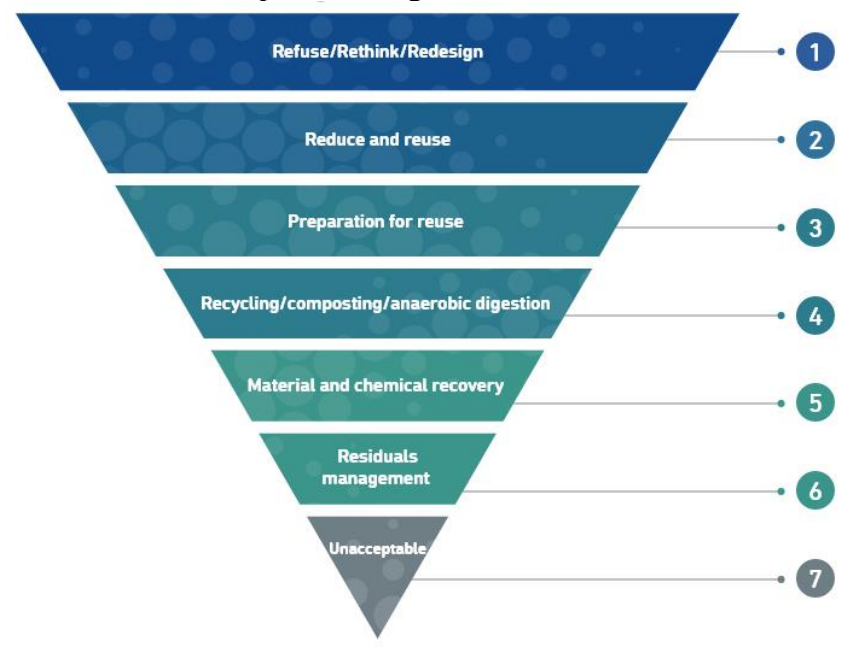

Figure 1. Zero Waste Hierarchy [4]

\section{Zero Waste City}

A zero waste approach emphasizes environmental stability by returning control over resource management and giving greater influence over the shape of the local economy to the community. Whether it's implemented through encouraging community composting, creating closed-loop systems by promoting reuse or by redesigning business models in the local production, zero waste helps create a flexible system that can be customized to the specific needs of the community. The positive benefits of this approach are that communities feel a sense of ownership, cohesion and pride over how their local area operates. In the future it is not only possible, but realistic for societies to design a circular system. Producers become consumers and consumers become producers. Disposable products and packaging will be replaced with reusable waste-free solutions, enabled by the shortening of supply chains. Local material flows become prioritised, and the community plays an active role in the management of resources to ensure they maintain the majority of the wealth that is generated by the new system. Through the growth of zero waste cities globally, we are beginning to see the benefits of it play out across all aspects of society, both for the environment and the people living in it, taking us one step closer each time to a zero-waste world. The concept of "zero waste city" is gradually being accepted globally. 25 cities around the world are making significant steps towards zero waste including Vancouver, Bute, Dubai, Flanders, Gipuzkoa, Cappanori, Hout Bay, Guam, Cashel, Buenos Aires, New York City, San Francisco, Ljubljana, Kamikatsu, Santa Monica, Pune, Medimurje, Sardinia, Taiwan, Sweden, San Diego, Wales, Targu Lapus, Alaminos, and Auckland [5]. A zero waste city concept emphasizes on promoting green development methods and lifestyles, reducing the amount of waste, and strengthening the recycling activities as well as minimizing waste sent to landfills and reducing impact of solid waste on the environment. Constructing a zero waste city involves many fields of knowledge and takes numerous steps as well as requires cooperation from involving sectors including consumers in the city. It requires clean production in the industries, green economic development and green lifestyles in communities. As a result, the process requires a new model of cooperative participation from government agencies, companies, social organizations and the public.

Moving towards zero waste, a city needs to measure its performance of waste management system. Zero waste index is developed based on the evidenced-based research methodology and is analysed by measuring the performance of waste management systems in the cities of Adelaide, San Francisco and Stockholm. The performance of waste management systems is measured by the waste diversion rate. The zero waste index forecasts the amount of materials, energy, water and greenhouse gas emissions substituted by the resources that are recovered from waste streams. The zero waste index can evaluate the potential energy, greenhouse gas (GHG) and water savings due to resource recovery from municipal solid waste in each of the three cities. It is obvious that the zero waste index is used as an innovative tool for evaluating waste management performance and materials substitution which are done by waste management systems in different cities [6]. (figure 2) 


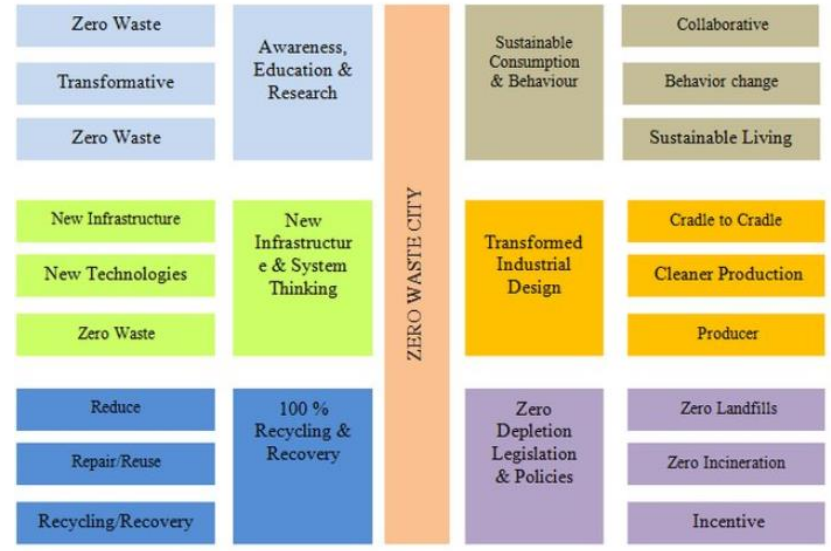

Figure 2. The Principles for Transforming the City into Zero Waste. [7]

Many Cities aim to eliminate waste disposal by 2050 by reducing waste generation and increasing diversion, reaching at least $70 \%$ diversion by 2030 . Moving towards zero waste, cities must transform solid waste and material management systems to reach at least $70 \%$ diversion [8]. Cities can begin zero waste implementation by increasing rates of recycling and recovery of wet and dry materials, from plastics and metals to food and organic waste, by improving waste separation at the collection sites. Cities that have better waste management system, the goal should include elimination of single-use items and non-recyclable materials, particularly plastics; and include higher rates of recovery and reuse of other materials such as fabrics, wood and potentially plastics. Slovenia, as an example of outstanding zero waste movement, is one of the cleanest and most environment-friendly countries, both in Europe and globally [9].

In Thailand, the National Solid Waste and Hazardous Waste Management Master Plan (2016 - 2021), has been issued by the Pollution Control Department (PCD) to be guidelines for local administration and related waste agencies to effectively manage garbage and waste and minimize their negative impacts on people's health [10]. As the waste disposal capacity is varied from agency to agency, they are allowed to choose a suitable method to dispose garbage for the amount ranging from no more than 15 tons a day to more than 700 tons a day and to decide on other factors such as location, environmental impact and community acceptance [11]. By studying experiences from other countries, Thailand hopes to launch its own law in banning single-use plastics in 2024 and aims to see all plastic waste returned to the manufacturing system -- the so-called zerowaste community -- in 2027 [12].

Plastic has become an important and integral part of Thai society due to its wide range of applications, such as packaging, agriculture, automobile parts, electronic applications and medical devices. Consequently, the amount of plastic waste is increasing every year due to the increase in plastic consumption caused by the increasing population. Plastic waste in Thailand basically comes from industrial processes and households and the amount keeps increasing, which consequently results in the problem of waste management. Additionally, the leakage of plastic waste into the ocean is another disruptive factor in Thailand's waste management. Therefore, the $3 \mathrm{R}$ concept; reduce, reuse, and recycle, have to be applied to minimize the impacts of plastic waste [13].

Through the National 3R Strategy and the National Master Plan (2016-2021), Thailand can ensure the proper waste management. Furthermore, several approaches were included in the "2017-2021 Plastic Debris Management Plan to promote the effectiveness of waste management such as introduction and promotion of eco-packaging design, implementation of the 3Rs (reduce-reuse-recycle) strategy for plastic debris management, the development of material flow for plastic containers and packaging inventory, and the promotion of education for relevant stakeholders in the field of plastics and its alternative materials. Besides, waste management legislation and law revision are implemented to improve the efficiency of plastic waste management, for example, imposing plastic bag fees, strengthening the $3 \mathrm{Rs}$ measures, and promoting circular economy in plastic value chains [14].

Under the concept of zero waste, the 3R strategy-Reduce, Reuse, and Recycle, can be applied to the Thai petrochemical industry at the factory level in order to manage industrial plastic waste in a sustainable way. The $3 R$ strategy, if fully implemented, could reduce the amount of landfill waste by over $20 \%$ of the amount produced. As a result, the disposal costs and consumption of natural resources could be reduced as well [15].

\section{What Benefits Can A City Gain From Going Zero Waste?}

Due to the limited availability of natural resources, especially non-renewable resources, zero waste approach has been adopted by cities around the world with the aim to eliminate waste and its toxic materials while saving the remaining natural resources. Zero Waste (ZW) is a holistic solution in managing waste and resources in a city in a sustainable way [16]. Moreover, zero waste has also changed people's attitude towards wase since waste that is considered to have no benefit can become economically valuable in the zero waste management system. Waste even becomes more valuable when it is properly recycled [17].

Achieving zero waste requires strong commitment and cooperation from all stakeholders, but its benefits are worth it. Benefits of zero waste can be assigned in four areas including benefits to the community, benefits to economy, benefits to the environment, and benefits to household.

Benefits to the community: Zero waste approach can promote social equity and enhance community formation. It also supports marginalized community, builds community capacity, and protects the community health. When focusing on reusing resources, the community can distribute the useful products to the people who are in need. For example, leftover food can be donated to the poor, used furniture can be donated to refugees, and the slightly used clothes can be reused by other community members. For the communitybased organic waste management, such as composting at a community garden, people in community can share tools and skills for reuse, repair, and recycle which allows everyone to participate in protecting the environment. They can reduce waste and pollution in the air, water, and soil which protects the health of the community [18]. 
Benefits to economy: In zero waste management system, waste of one person can be material/resource for something new. It creates more jobs in the community as composting, recycling, and diverting require more people to do the jobs than the disposing does [19]. In addition, resource recovery is a high-labor activity that provides a variety of jobs to different groups of people, from vulnerable members of the community to highly-skilled workers [20]. Zero waste strategies also helps the community becomes less dependent on imported materials and products, thus, local funds are spent on local products and services instead of going outside the community. Besides saving the money, it also helps reduce $\mathrm{CO} 2$ emission due to the reduction of transport [21].

Benefits to the environment: Zero waste strategies, including planning our meals ahead, reducing unnecessary food purchase, delivering leftovers to those in need, and composting to reduce organic waste from landfills, can help us reduce the emission of greenhouse gases such as carbon dioxide and methane - a greenhouse gas more potent than carbon dioxide [22]. Also, compost from organic waste can be used as fertilizer to improve soil structure and quality for growing new food. Moreover, zero waste helps conserve natural resources and minimizes pollutions that come from extracting, manufacturing, and disposal.

Benefits to household: Going zero waste means reducing unnecessary purchase of products, thus, a household can save more money. Also, when mindfully buying foods, a family will reduce and eventually eliminate packaged processed foods and snacks which will allow the family members eat healthier foods and get healthier.

\section{Sufficiency Economy Philosophy}

In the consumption driven society, high consumption can be used to drive a country's GDP, but this consequently destroys the ecosystem. Consumption means the acquisition and use of resources leading to the depletion of Earth's limited resources [23]. American population, for example, makes up just 4 percent of the world's population, but generating 12 percent of the planet's yearly waste. According to the United States Environmental Protection Agency (E.P.A.), the country's annual waste sent to landfills include 840,000 tons of plastic plates and cups, 3.4 million tons of diapers, 8.2 million tons of clothing and footwear and 910,000 tons of towels, sheets and pillowcases [24]. For Thailand, 26,850,000 tons of municipal waste is yearly generated. Out of this amount, food and organic waste takes up 64\% [25]. Therefore, it is important to understand that human's consumption behaviors are related to waste generation, and we need a new model of economic activity that benefits quality of life while allowing the ecosystem to recover.

Consumerism and shorter cycle of consumption is considered as a major cause of the increasing waste of resources and volume of refuse such as community garbage, industrial waste, hazardous waste, and emission of carbon dioxide and toxic gases. Higher demand of the increasing population leading to higher demand of resources and volume of refuse as well as wasteful manufacturing processes and technologies also cause pollution. In addition, inappropriate use of land exceeding the earth's carrying capacity is responsible for increasing pollutants while limitations of manpower, budget, and bodies of knowledge make it more difficult for communities to handle the increasing waste and pollutants. Waste situation is getting worse when public awareness, participation in administration processes, and economic tools in pollution management remain limited.

If the waste problems have been closely examined, the root of the problems could be seen. Never-ending requirement, overconsumption, excessive possession, and unawareness of the negative consequence of self-actions are the main causes of extreme waste problems, pollutions, and too much extraction of natural resources. To sustainably tackle with waste problems at roots, sufficiency economy philosophy (SEP) is considered as a systematic guidance for waste management plans and strategies. Sufficiency economy philosophy, developed by the King Bhumibol Adulyadej of Thailand, is a practical guidance suitable for everyone to follow. It consists of three principles: moderation (not excessive or not extreme), reasonableness (being aware of the connection between actions and consequences), and prudence (being immune to the internal and external changes) [26]. Besides, there are two preconditions attached to these principles: virtues (positive values of a person or positive norms of a group) and knowledge (simply what is known or empirical evidence).

Sufficiency Economy Philosophy (SEP) relates to Buddhist principles of middle path which encourages an individual to live his life with self-reliance and self-satisfaction. It guides people at all levels to improve their livelihood and behavior while promoting balanced development in a sustainable way. Sufficiency, meaning not excessive/not extreme, can be applied in both production and consumption phases. When being applied to consumption, consumers make their choices of consumption with care for themselves and for others and being aware that overconsumption can lead to problems of waste, pollution, and depletion of natural resource. Consumers who follow sufficiency philosophy consume only what they really need and choose products carefully. Moderation influences consumers to stop themselves from never-ending requirement and rethink if it is a need or a want. With reasonableness, they realize that over-consumption/purchase /production will cause excessive waste and pollutions that harm people and environment at the end. Prudence influences consumers to examine what he/she can do to support the two top priorities of $3 \mathrm{R}$ strategies: Reduce and Reuse. Virtue will guide them to consume with responsibility as they care for others and avoid harming each other and the environment while knowledge helps them understand the real problems/situation of waste and pollutions which will lead them to follow this path whenever they make their choice in consumption. (Figure 3 ) 


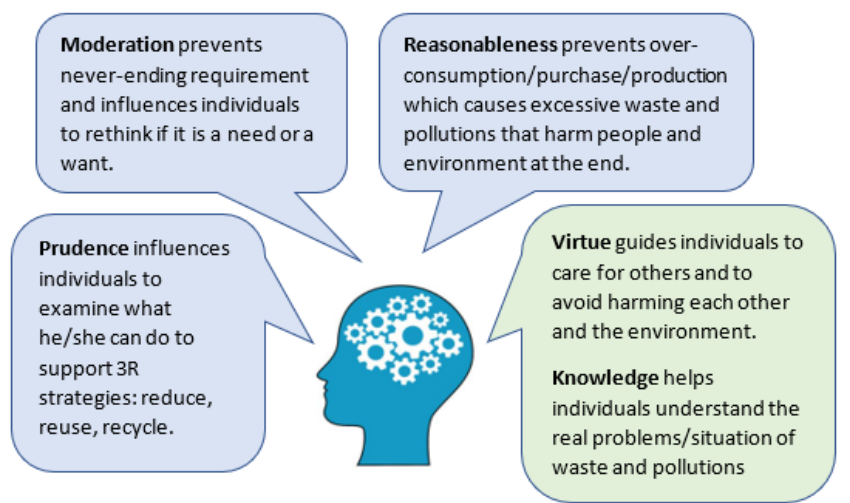

Figure 3. Consumption Behavior in Sufficiency Economy Philosophy Framework

The Sufficiency Economy Philosophy also can be used in all sectors in the country including waste management. Moving towards zero waste, a city need to raise awareness and realization of both the producers and consumers to construct sufficiency mindset and to create knowledge-based attitudes towards zero waste lifestyle. It is also essential to increase awareness among stakeholders to realize the value of waste and treat it as valuable secondary raw material while properly including the $3 \mathrm{R}$ (Reuse, Recycle, and Reduce) in their business practice perspective. At the same time, people in community can actively participate in the process of recycle besides their cooperation in reduce and reuse. It is important to encourage people in community to follow zero practices in separating waste for recycling and exercise reasonably purchasing habits with the aim to reduce waste. Following the sufficiency economy philosophy, a city can achieve zero waste goal in a sustainable manner, including the minimization of waste generation while maximizing the waste recycling.

The environmental crisis and natural resource depletion make people realize that unbalanced development plans and overconsumption have negative impacts on the natural and environmental resource capitals. Besides being applied to waste management system, Sufficiency Economy Philosophy can be applied as strategies for development of biodiversity and conservation of the environment and natural resources including three 3 approaches - maintaining resource bases and balancing the conservation and utilization of resources; creating good environment to upgrade people's quality of life and sustainable development; and improving the value of biodiversity and local wisdom to strengthen the foundation of economic structure for long-term biodiversity-based development. The strategic implementation in accordance with those approaches will help maintain the prosperity of natural resources to support fundamental living of people and keep the environmental problems under control so they do not disturb the delicate condition of the ecosystem for living as well as preserve the resource biodiversity which is an opportunity to make use of the existing changing context and to relate people's ways of living and local wisdom to new knowledge and innovations.

Waste solutions and waste management towards zero waste cannot be achieved by a sector or by an organization. It, however, needs helps and supports from everyone in the society. Therefore, every sector should take into consideration and unite to find an efficient solution. Consumer behaviour based on sufficiency economy philosophy can be considered as one of contributions to zero waste management. The solution of the solid waste problem could have a positive impact on the national economy; promoting tourist visits, alleviating environmental degradation, reduce water contamination and air pollution which is a source of disease transmission.

\section{Conclusion}

Every year more and more waste is generated and the situation is exacerbated by our overconsumption behaviors. A huge volume of waste is sent to landfills and incinerators. Landfill sites can be a constant threat to the environment as they take up large pieces of land to exist; causing damage to ecosystems, they are a blot on the landscape in our natural surroundings, and they are one of the major causes of toxic contamination of soil. Burning waste in incinerators also pollutes the air by producing hazardous air pollutants such as carbon monoxide and PM 2.5 and it needs strong environmental controls.

The current linear economy; take-make-use-dispose, can be identified as a major cause of the excessive amount of waste. Thus, zero waste strategies help manage our resource in a way of preserving their value and energy in a circularity chain and lead to waste reduction while our consumption behavior has to be changed in order to keep our planet away from excessive waste and toxic conditions. To make this happen, a waste preventive policy must be adopted to promote reduce, reuse, and rethink practices, followed by increasing separation in the waste collection at source and quality recycling. Significantly, overconsumption culture needs to be changed to ensure that we are not taking resources and wasting them over our planet capacity.

To stop the production of excessive waste and the uncontrolled climate change, cities need to replace their waste addictive behavior with sufficiency lifestyle. Sufficiency Economy philosophy is a practical guideline for the traditional lifestyle of Thai society in which all aspects of life are interconnected because it allows peaceful coexistence of different things. Sufficiency, meaning not excessive/not extreme, can be applied in both production and consumption phases. When applying the philosophy to consumption, people become more aware of the negative consequences of overconsumption and they will make their choices of consumption with care for themselves and others as well as with care for the environment and the sustainability for the future generations.

\section{References}

[1] ZWIA. (2018). Zero Waste Hierarchy of Highest and Best Use 7.0. Retrieved on 28 November 2020, from http://zwia.org/zwh/

[2] Zero Waste Europe. (2019). A Zero Waste hierarchy for Europe. Retrieved on 21 November 2020, from 
https://zerowasteeurope.eu/2019/05/a-

zero-waste-hierarchy-for-europe/

[3] Zero Waste Cities. (2019). Discover What is a zero waste city? Retrieved on 15 December 2020, from https://zerowastecities.eu/discover/

[4] Nationalgeographic.com (2018). Retrieved on 18 November 2020, from https://www.nationalgeographic.com/trave 1/lists/zero-waste-eliminate-sustainabletravel-destination-plastic/

[5] Zaman, A. \& Lehmann, S. (2013). The zero waste index:a performance measurement tool for waste management systems in a zero waste city. Journal of Cleaner Production. 50 (7): 123-132.

[6] Arkin, C. (2019). Zero waste cities: A key solution to the climate crisis. Retrieved on 1 December 2020, from https://zerowasteworld. org/zwclimate/

[7] SENSA Networks. (2019). 10 Cities that are making zero waste a reality for a sustainable future. Retrieved on 1 December 2020, from http://www.sensanetworks.com/ blog/10cities-that-are-making-zero-waste-areality-for-a-sustainable-future/

[8] PCD. (2016). Plastic waste master plan 2017-2021. Retrieved on 22 November 2020, from http://www.pcd.go.th/count/lawdl.cfm?Fil e Name=DraftWastePlan60-64.pdf.

[9] Simachaya. (2018). Solid Waste Management in Thailand: Policy and Imple- mentation. Retrieved on 2 December 2020, from https://hlsesc.org/documents/

8hlsesc/Thematic\%20C1/Thematic\%20\%2 0C1\%20-\%20Thailand\%20_\%20solid $\% 20$ Waste $\% 20$ Management $\% 20 \mathrm{in} \% 20 \mathrm{Th}$ ailand $\% 2 \mathrm{C} \% 20$ Policy $\% 20$ and $\% 20$ Implem entation\%20by\%20Dr.\%20Wijarn\%20Sim achaya.pdf

[10] Bangkok Post. (2020). Toward zero waste. Retrieved on 23 November 2020, from https://www.bangkokpost.com/life/socialand-lifestyle/1859289/toward-zero-waste
[11] Piyapanpong, S. (2018). Thailand's 3R strategy. Retrieved on 2 December 2020, from

http://www.uncrd.or.jp/content/documents/ Session4_Piyapanpong.pdf

[12] Wichai-utcha, N. \& Chavalparit, O. (2019). 3Rs Policy and plastic waste management in Thailand. Journal of Material Cycles and Waste Management. volume 21:10-22.

[13] Usapein, P. \& Chavalparit, O. (2014). Development of sustainable waste management toward zero landfill waste for the petrochemical industry in Thailand using a comprehensive 3R methodology: A case study. Waste Manag Res Waste Manag Res. 32(6):509-18.

[14] Zaman \& Lehmann. (2011). What is the 'Zero Waste City' Concept? Retrieved on 23 November 2020, from https://nswai.com/docs/What\%20is\%20the \%20Zero\%20Waste\%20City\%20Concept. pdf

[15] Nizar et al. (2018). Examining the Economic Benefits of Urban Waste Recycle Based on Zero Waste Concepts. Retrieved on 27 November 2020, from https://www.atlantis-

press.com/proceedings/agc-18/55911061

[16] "Benefits of Zero Waste". Retrieved on 27 November 2020, from https://www.torontoenvironment.org/zero waste_benefits

[17] "The Benefits of Community Recycling". Retrieved on 7 December 2020, from https://zerowaste.co.nz/assets/TheBenefits-of-Community-Recycling.pdf

[18] "16 Surprising Benefits Of Going Zero Waste". Retrieved on 29 November 2020, from

https://www.almostzerowaste.com/zerowaste-benefits/

[19] "Fight climate change by preventing food waste". Retrieved on 4 December 2020, from https://www.worldwildlife.org/stories/fight -climate-change-by-preventing-food- 
waste\#: :text=Today $\% 2 \mathrm{C} \% 20 \mathrm{an} \% 20$ estim ated $\% 20$ one $\% 2$ Dthird,the $\% 20$ world $\% 20 \mathrm{~g}$ oes $\% 20$ to $\% 20$ waste. $\&$ text $=$ And $\% 20$ if $\% 20$ food $\% 20$ goes $\% 20$ to,if $\% 20 \mathrm{we} \% 20$ stop $\% 20$ wasting\%20food.

[20] Zaman \& Lehmann. (2011). Challenges and Opportunities in Transforming a City into a 'Zero Waste City'. Retrieved on 23 November 2020, from https://www.researchgate.net/publication/2 57409801_Challenges_and_Opportunities _in_Transforming_a_City_into_a_'Zero_ Waste_City'

[21] "Consumption, Waste and our Changing Lifestyle". (2019). Retrieved on 2 December 2020, from https://blogs.ei.columbia.edu/2019/08/26/c onsumption-waste-changing-lifestyle/

[22] Municipal Solid Waste Management in Thai Local Governments: The State of the problem and prospects for regional waste management. (2019). Retrieved on 29 November 2020, from https://www.ide.go.jp/library/English/Publ ish/Download/Ec/pdf/201903_ch04.pdf

[23] Bergsteiner \& Dharmapiya. (2016). Sufficiency economy philosophy process. In G. C. Avery \& H. Bergsteiner (Eds.), Sufficiency Thinking: Thailand's gift to an unsustainable world. Sydney: Allen \& Unwin. 